\title{
A national case-control study of risk factors for listeriosis in Australia
}

\author{
C. B. DALTON ${ }^{1,2 *}$, T. D. MERRITT ${ }^{1}$, L. E. UNICOMB ${ }^{3}$, M. D. KIRK ${ }^{4,5}$, \\ R. J. STAFFORD ${ }^{6}$, K. LALOR ${ }^{7}$ and the OzFoodNet Working Group \\ ${ }^{1}$ Hunter New England Population Health, Wallsend, NSW, Australia \\ ${ }^{2}$ Conjoint with School of Medical Practice and Population Health, University of Newcastle, Callaghan, NSW, \\ Australia \\ ${ }^{3}$ Programme on Infectious Diseases and Vaccine Sciences, Health Systems and Infectious Diseases Division, \\ International Centre for Diarrhoeal Disease Research, Bangladesh \\ ${ }^{4}$ Australian Government Department of Health and Ageing, Woden, ACT, Australia \\ ${ }^{5}$ National Centre for Epidemiology \& Population Health, The Australian National University, Canberra, ACT, \\ Australia \\ ${ }^{6}$ OzFoodnet, Queensland Health Department, Brisbane, Queensland, Australia \\ ${ }^{7}$ OzFoodNet, Department of Human Services, Victoria, Australia
}

(Accepted 30 March 2010; first published online 30 April 2010)

\section{SUMMARY}

Listeriosis is a foodborne disease associated with significant mortality. This study attempts to identify risk factors for sporadic listeriosis in Australia. Information on underlying illnesses was obtained from cases' treating doctors and other risk factors were elicited from the patient or a surrogate. We attempted to recruit two controls per case matched on age and primary underlying immune condition. Between November 2001 and December 2004 we recruited 136 cases and 97 controls. Of perinatal cases, living in a household where a language other than English was spoken was the main risk factor associated with listeriosis (OR 11·3, 95\% CI 1·5-undefined). Of non-perinatal cases we identified the following risk factors for listeriosis: prior hospitalization (OR 4.3, 95\% CI 1·0-18·3), use of gastric acid inhibitors (OR 9·4, $95 \%$ CI 2·4-37.4), and consumption of camembert (OR $4 \cdot 7,95 \%$ CI $1 \cdot 1-20 \cdot 6$ ). Forty percent of cases with prior hospitalization were exposed to high-risk foods during hospitalization.

Key words: Foodborne infections, Listeria, public health.

\section{INTRODUCTION}

Listeriosis is a serious foodborne infection with a mortality rate of about $10-44 \%$ in foodborne outbreak cases [1]. Cases occur predominantly in the elderly, immunocompromised, and pregnant women and their neonates. Neonatal infection follows

\footnotetext{
* Author for correspondence: Dr C. B. Dalton, Hunter New England Population Health, Booth Building, Locked Bag 10, Wallsend 2287, NAW, Australia.

(Email: craig.dalton@hnehealth.nsw.gov.au)
}

maternal sepsis and chorioamnionitis and can result in abortion, stillbirth, premature delivery or neonatal meningitis in those developing illness in the weeks after delivery. Common manifestations of listeriosis in adults include meningoencephalitis and a wide range of focal infections in organ systems and prostheses [2].

In Australia, the incidence of listeriosis is low with about $2 \cdot 5-3 \cdot 6$ cases per million population per annum. Doctors and laboratories notifiy about 50-60 nonperinatal and 5-10 materno-fetal infections to health 
departments annually [3]. Multiple risk factors and high-risk foods have been identified from outbreak investigations, case-control studies, and risk assessments overseas. High-risk foods include ready-to-eat foods, which are often of animal origin, and 'delicatessen style' processed foods such as processed meats, soft cheeses and smoked seafood, and a wide range of fruit and vegetable products [4]. Food safety authorities worldwide use these findings to develop advice for populations particularly vulnerable to listeriosis, such as the immunocompromised, pregnant women, and the elderly, and to guide food safety programmes. Most cases of listeriosis in Australia appear to be sporadic and local evidence for risk factors for listeriosis are limited to investigations of six clusters over the last 30 years that have been associated with mussels, processed meats, sandwiches and fruit salad $[5,6]$. The aim of this case-control study was to identify dietary, medical and behavioural risk factors for invasive listeriosis in Australia and describe the spectrum of illness in patients with listeriosis.

\section{METHODS}

From November 2001 to December 2004, Australian State and Territory health departments attempted to interview all notified cases of listeriosis within 1 month of collection of a specimen that was positive by culture for Listeria monocytogenes. Listeriosis is a laboratory notifiable condition in all states and territories of Australia based on the culture of L. monocytogenes from a normally sterile site. Perinatal cases were defined as illness in a pregnant woman, fetal loss, or illness in a baby aged $<3$ months with isolation of L. monocytogenes from at least one of the maternofetal pair from any of the following sites: the placenta or products of conception, fetal gastrointestinal contents, or a normally sterile site from a pregnant woman, fetus or baby. Pregnant women were recruited to case status for the purpose of identifying risk factors for infection. Non-perinatal cases were defined as all other cases with L. monocytogenes isolated from blood, cerebrospinal fluid or other normally sterile site. Cases were excluded if they were: (1) asymptomatic, except for perinatal mothers, (2) part of an outbreak associated with an identified food vehicle, (3) unable to be contacted within 4 weeks of culture date, and (4) where the treating doctor or family member refused participation.

We attempted to recruit two controls per case, except in Victoria where only cases were recruited to the study. For non-perinatal cases, we attempted to recruit two age-matched controls per case from clinics specializing in the treatment of the case's primary underlying immune condition. Where there was no known immunocompromising condition, age-matched controls were selected from a general practitioner's clinic. Perinatal controls were recruited from hospital-based antenatal clinics and had gestational attainment within 4 weeks of the matched case at the time of the positive culture. All controls were recruited within 4 weeks of conducting the case interview.

Interviewers conducted telephone interviews with cases, or their surrogates, and controls using a standard questionnaire. Information on the case's major underlying immunocompromising condition was obtained from the treating doctors, while other risk factors were elicited from the patient or a surrogate. Participants were asked about consumption of 43 food items, considered to be high risk for listeriosis in previous studies, that were consumed in the 4 weeks prior to specimen collection date for cases and the corresponding 4 weeks for perinatal controls and the 4 weeks prior to interview date for non-perinatal controls. Information on the frequency of consumption (weekly, 2-3 times per month, or monthly), place of preparation, site of purchase or consumption, and, where appropriate, whether eaten raw or cooked were collected for each item. Prior hospitalization was defined as 7-28 days prior to specimen collection date for cases or interview date for controls.

Descriptive, univariate and multivariate logistic regression analyses were conducted using Stata Intercooled version 10 (Stata Corp., USA) for both perinatal and non-perinatal cases and controls. All case-control analyses were matched. Conditional logistic regression was used for non-perinatal data and all variables with $P$ values $\leqslant 0 \cdot 25$ were included in multivariate models for further assessment. Final multivariate models were derived using a forwards stepwise approach. Model specification was assessed using the link test. Exact (matched) logistic regression was used for the perinatal data.

Within each jurisdiction, ethics approval was gained through the relevant State or regional ethics committees.

\section{RESULTS}

We recruited 136 cases from 1 November 2001 to 31 December 2004. Cases were recruited in all States and 


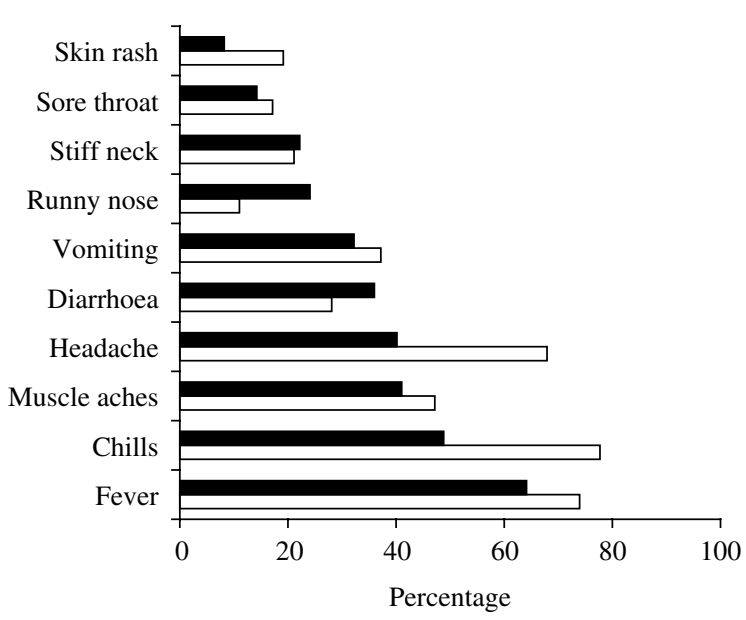

Fig. 1. Prevalence of symptoms in non-perinatal (ם) and perinatal $(\square)$ cases in the 4 weeks before specimen collection, Australia 2001-2004.

Territories with $113(83 \%)$ recruited cases resident in NSW (53), Victoria (34), Western Australia (26). Cases in other jurisdictions were as follows: Queensland (14), South Australia (5), ACT (2), Northern Territory (1) and Tasmania (1). Jurisdictions began recruiting at different times; however, we recruited 136 $(71 \%)$ of the 193 incident cases that were notified once jurisdictions had commenced the study. When all jurisdictions were participating 52/69 (75\%) cases notified nationally in 2003 and 47/67 (70\%) cases notified in 2004 were recruited. No outbreaks were detected during the study period.

There were $19(14 \%)$ perinatal cases of which L. monocytogenes was isolated from the materno-fetal pair in 10 cases, from the mother only in two cases and from the fetus only in seven cases. Median fetal gestational age at diagnosis was 35 weeks (range 18-40) with a total of four deaths between 18 and 32 weeks for a fetal case-fatality rate of $21 \%$.

Of the 117 non-perinatal cases, $55(47 \%)$ were female, $87(74 \%)$ were aged $\geqslant 60$ years and $47(40 \%)$ were aged $\geqslant 75$ years. The site of culture was blood for $92(79 \%)$, cerebrospinal fluid for $18(15 \%)$, and other sites for seven $(6 \%)$ cases. Twenty-two cases died giving a non-perinatal case-fatality rate of $19 \%$.

Fever, chills, and headache were reported more frequently in pregnant women than non-perinatal cases, and diarrhoea was more often reported by nonperinatal cases (Fig. 1).

Of all cases for whom information was available, 50/129 (39\%) cases came from households where a Language Other Than English (LOTE) was spoken and $42 / 88$ cases $(48 \%)$ were born in countries other than Australia. The geographic region of birth for
Table 1. Primary underlying immunocompromising condition for non-perinatal listeriosis cases as reported by the case's treating doctor, Australia, 2001-2004

\begin{tabular}{lcc}
\hline \hline Primary condition & Number & $\begin{array}{l}\text { Proportion } \\
(\%)\end{array}$ \\
\hline Cancer - haemotological & 30 & 26 \\
Cancer - solid & 21 & 18 \\
Diabetes & 10 & 9 \\
Renal disease & 8 & 7 \\
Heart disease & 6 & 5 \\
Arthritis & 4 & 3 \\
Liver disease & 4 & 3 \\
Organ transplant & 4 & 3 \\
Inflammatory bowel disease & 3 & 3 \\
HIV/AIDS & 2 & 2 \\
Lung disease & 2 & 2 \\
Lupus & 1 & 1 \\
Other & 2 & 2 \\
None identified & 20 & 17 \\
Total & $\mathbf{1 1 7}$ & $\mathbf{1 0 0}$ \\
\hline \hline
\end{tabular}

foreign-born cases was Europe (30 cases, predominantly Western and Southern Europe), Asia (eight cases), Middle East (one case) and Oceania (two cases) with missing data for one. The region of birth for 37 cases identified as living in households where a LOTE was spoken were Western Europe $(15,41 \%)$, Central Eastern Europe (5, 14\%), Asia (6, 16\%), Oceania (2, 5\%) and Australia (9, 24\%). Nine of 136 $(7 \%)$ cases were from rural areas, and 15/131 (12\%) were Aboriginal.

Treating doctors nominated the following conditions as the primary immunocompromising condition in the non-perinatal patients, haematological malignancy $(26 \%)$, solid cancers $(18 \%)$ diabetes $(9 \%)$, and renal disease $(7 \%)$ (Table 1$)$.

The most common immunocompromising medications used by non-perinatal cases in the 4 weeks prior to onset were antibiotics $(37 \%)$, corticosteroids $(36 \%)$, chemotherapy $(26 \%)$, and gastric acid inhibitors $(22 \%)$. Fifteen cases $(13 \%)$ were residents of aged care institutions where meals were provided for them. Thirty-nine cases (33\%) were admitted to hospital in the period 7-28 days prior to specimen collection.

Eighty-five controls were recruited for the 117 nonperinatal controls, 51 cases were matched to a control, 17 with one control each and 34 with two controls each. Twelve controls were recruited for the 19 perinatal cases, six cases were matched to two 
Table 2. Case-specific risk factors for non-perinatal and perinatal listeriosis, Australia, 2001-2004

\begin{tabular}{|c|c|c|c|c|c|c|c|c|c|c|c|c|}
\hline \multirow[b]{3}{*}{ Risk factor } & \multicolumn{6}{|c|}{ Non-perinatal } & \multicolumn{6}{|c|}{ Perinatal } \\
\hline & \multicolumn{2}{|l|}{$\begin{array}{l}\text { Cases } \\
\text { exposed }\end{array}$} & \multicolumn{2}{|c|}{$\begin{array}{l}\text { Controls } \\
\text { exposed }\end{array}$} & \multirow[b]{2}{*}{$\mathrm{mOR}$} & \multirow[b]{2}{*}{$95 \% \mathrm{CI}$} & \multicolumn{2}{|c|}{$\begin{array}{l}\text { Cases } \\
\text { exposed }\end{array}$} & \multicolumn{2}{|c|}{$\begin{array}{l}\text { Controls } \\
\text { exposed }\end{array}$} & \multirow{2}{*}{$\begin{array}{l}\text { Exact } \\
(\mathrm{mOR})\end{array}$} & \multirow[b]{2}{*}{$95 \% \mathrm{CI}$} \\
\hline & $n$ & $\%$ & $n$ & $\%$ & & & $n$ & $\%$ & $n$ & $\%$ & & \\
\hline $\begin{array}{l}\text { Aboriginal or Torres } \\
\text { Strait Islander }\end{array}$ & $11 / 117$ & $9 \cdot 4$ & $5 / 85$ & $5 \cdot 9$ & $2 \cdot 0$ & $0 \cdot 6-7 \cdot 4$ & $4 / 19$ & $21 \cdot 0$ & $4 / 12$ & $33 \cdot 3$ & $1 \cdot 0$ & $0 \cdot 0-97 \cdot 9$ \\
\hline LOTE & $37 / 117$ & $31 \cdot 6$ & $6 / 85$ & $7 \cdot 1$ & $3 \cdot 2$ & $1 \cdot 1-9 \cdot 4$ & $13 / 19$ & $68 \cdot 4$ & $1 / 12$ & $8 \cdot 3$ & $11 \cdot 3 \dagger$ & 1.5-undefined \\
\hline Overseas born & $33 / 117$ & $28 \cdot 2$ & $15 / 85$ & $17 \cdot 7$ & $1 \cdot 7$ & $0 \cdot 7-4 \cdot 1$ & $9 / 19$ & $47 \cdot 4$ & $1 / 12$ & $8 \cdot 3$ & $7 \cdot 7 \dagger$ & $0 \cdot 8$-undefined \\
\hline Resident ACF & $15 / 117$ & $12 \cdot 8$ & $4 / 85$ & $4 \cdot 7$ & $2 \cdot 6$ & $0 \cdot 6-11 \cdot 1$ & $0 / 19$ & $0 \cdot 0$ & $3 / 12$ & $25 \cdot 0$ & $0 \cdot 4 \dagger$ & $0 \cdot 0-5 \cdot 1$ \\
\hline \multicolumn{13}{|l|}{ Prior medications } \\
\hline Prednisolone & $42 / 117$ & $35 \cdot 9$ & $20 / 85$ & $23 \cdot 5$ & $3 \cdot 7$ & $1 \cdot 3-10 \cdot 9$ & $0 / 19$ & $0 \cdot 0$ & $0 / 12$ & $0 \cdot 0$ & $*$ & \\
\hline Antibiotics & $43 / 117$ & $36 \cdot 8$ & $18 / 85$ & $21 \cdot 2$ & $3 \cdot 1$ & $1 \cdot 3-7 \cdot 5$ & $1 / 19$ & $5 \cdot 3$ & $0 / 12$ & $0 \cdot 0$ & $*$ & \\
\hline Antacids & $21 / 117$ & $18 \cdot 0$ & $22 / 85$ & $25 \cdot 9$ & $1 \cdot 1$ & $0 \cdot 5-2 \cdot 7$ & $4 / 19$ & $21 \cdot 1$ & $4 / 12$ & $25 \cdot 0$ & $0 \cdot 4$ & $0 \cdot 0-8 \cdot 1$ \\
\hline $\begin{array}{l}\text { Gastric acid } \\
\text { suppressants }\end{array}$ & $26 / 117$ & $22 \cdot 2$ & $11 / 85$ & $12 \cdot 9$ & $6 \cdot 2$ & $2 \cdot 0-18 \cdot 6$ & $0 / 19$ & $0 \cdot 0$ & $0 / 12$ & $0 \cdot 0$ & $*$ & \\
\hline $\begin{array}{l}\text { Prior hospitalization } \\
\text { (7-28 days) }\end{array}$ & $39 / 117$ & $33 \cdot 3$ & $9 / 85$ & $10 \cdot 6$ & $4 \cdot 4$ & $1 \cdot 6-12 \cdot 2$ & $0 / 19$ & $0 \cdot 0$ & $1 / 12$ & $8 \cdot 3$ & $*$ & \\
\hline
\end{tabular}

mOR, Matched odds ratio; CI, confidence interval; LOTE, language other than English; ACF, aged care facility.

* Unable to calculate as numerator or denominator $=0$ in matched analysis.

$\dagger$ Median unbiased estimates.

controls each. Controls for non-perinatal cases were recruited from NSW (55, 65\%), Queensland (13, $15 \%)$, Western Australia (13, 15\%), and South Australia (4, 5\%). Controls for perinatal cases were recruited from NSW (8, 67\%), and Western Australia $(4,33 \%)$. A higher percentage of non-perinatal cases $(47 \%)$ than non-perinatal controls $(38 \%)$ were female. A similar percentage of cases $(74 \%)$ and controls $(71 \%)$ were aged $\geqslant 60$ years.

In univariate analysis, risk factors for non-perinatal listeriosis cases included living in a household where a LOTE was spoken; prior hospitalization; and any one of antibiotic, prednisolone or gastric acid inhibitor administration in the 4 weeks prior to admission (Table 2), and consumption of liverwurst (Table 3). No food history was available for five of the nonperinatal cases.

Multivariate analysis of non-perinatal cases identified the following risk factors for listeriosis: prior hospitalization (OR $4 \cdot 3,95 \%$ CI $1 \cdot 0-18 \cdot 3$ ), use of gastric acid inhibitors (OR 9.4, 95\% CI 2.4-37.4), and consumption of camembert (OR 4.7, 95\% CI 1.1-20.6). Model specification was assessed using the link test and found to be acceptable. Analysis of risk factors for perinatal cases identified living in a household where a LOTE was spoken as the only risk factor associated with listeriosis (OR 11.3, 95\% CI 1.5-undefined). No association was found between the frequency of consumption of any other individual foods and perinatal or non-perinatal listeriosis (data not shown). Many other case-specific and foodspecific risk factors were examined but no meaningful associations with Listeria infection were identified (see Appendix Tables 1 and 2).

Of LOTE cases, only $1 / 8(13 \%)$ perinatal cases and $1 / 19(5 \%)$ non-perinatal cases reported that a healthcare worker had warned them to avoid specific foods to prevent Listeria prior to their illness with listeriosis. This compares with $3 / 5(60 \%)$ perinatal cases and $10 / 61(16 \%)$ non-perinatal cases in non-LOTE households.

Of the patients that were hospitalized or made clinic visits in the 2 months prior to their listeriosis diagnosis, the following high-risk foods were reportedly consumed during their visit, lettuce 11/39 patients (28\%), diced chicken sandwiches 5/39 $(13 \%)$, ham sandwiches $15 / 40(38 \%)$, fresh fruit salad $8 / 39(21 \%)$, soft cheese $4 / 39(10 \%)$ rockmelon (cantaloupe) or strawberries 9/39 (23\%). Eighteen of $45(40 \%)$ cases consumed at least one of these highrisk foods during hospitalization. For these 18 cases, the following immunocompromising conditions were identified: age $>75$ years (1), haematological cancer (8), solid cancer (3), HIV/AIDS (1), heart disease (2), organ transplant (1), renal impairment (1), and mixed connective tissue disease (1). 
Table 3. Food-specific risk factors for non-perinatal and perinatal listeriosis

\begin{tabular}{|c|c|c|c|c|c|c|c|c|c|c|c|c|}
\hline \multirow[b]{3}{*}{ Risk factor - foods } & \multicolumn{6}{|c|}{ Non-perinatal } & \multicolumn{6}{|c|}{ Perinatal } \\
\hline & \multicolumn{2}{|l|}{$\begin{array}{l}\text { Cases } \\
\text { exposed }\end{array}$} & \multicolumn{2}{|c|}{$\begin{array}{l}\text { Controls } \\
\text { exposed }\end{array}$} & \multirow[b]{2}{*}{$\mathrm{mOR}$} & \multirow[b]{2}{*}{$95 \% \mathrm{CI}$} & \multicolumn{2}{|c|}{$\begin{array}{l}\text { Cases } \\
\text { exposed }\end{array}$} & \multicolumn{2}{|c|}{$\begin{array}{l}\text { Controls } \\
\text { exposed }\end{array}$} & \multirow{2}{*}{$\begin{array}{l}\text { Exact } \\
(\mathrm{mOR})\end{array}$} & \multirow[b]{2}{*}{$95 \% \mathrm{CI}$} \\
\hline & $n$ & $\%$ & $n$ & $\%$ & & & $n$ & $\%$ & $n$ & $\%$ & & \\
\hline Rockmelon/cantaloupe & $50 / 112$ & $44 \cdot 6$ & $32 / 85$ & $37 \cdot 7$ & $2 \cdot 1$ & $1 \cdot 0-4 \cdot 7$ & $8 / 19$ & $42 \cdot 1$ & $3 / 12$ & $25 \cdot 0$ & $4 \cdot 0$ & $0 \cdot 2-236 \cdot 0$ \\
\hline Ready-to-eat fruit salad & $12 / 112$ & $10 \cdot 7$ & $11 / 85$ & $12 \cdot 9$ & $1 \cdot 6$ & $0 \cdot 5-4 \cdot 5$ & $3 / 19$ & $15 \cdot 8$ & $1 / 12$ & $8 \cdot 3$ & $2 \cdot 0 \dagger$ & $0 \cdot 0-78 \cdot 0$ \\
\hline Ready-to-eat other salad & $3 / 112$ & $2 \cdot 7$ & $16 / 85$ & $18 \cdot 8$ & $0 \cdot 2$ & $0 \cdot 0-0 \cdot 9$ & $2 / 19$ & $10 \cdot 5$ & $5 / 12$ & $41 \cdot 7$ & $0 \cdot 3$ & $0 \cdot 0-4 \cdot 3$ \\
\hline Chopped liver/liverwurst & $7 / 112$ & $6 \cdot 3$ & $1 / 85$ & $1 \cdot 2$ & $11 \cdot 1$ & $1 \cdot 3-92 \cdot 5$ & $1 / 19$ & $5 \cdot 3$ & $0 / 12$ & $0 \cdot 0$ & $*$ & \\
\hline Camembert & $14 / 112$ & $12 \cdot 5$ & $7 / 85$ & $8 \cdot 2$ & $2 \cdot 5$ & $0 \cdot 9-7 \cdot 4$ & $0 / 19$ & $0 \cdot 0$ & $2 / 12$ & $16 \cdot 7$ & $0.8 \dagger$ & $0 \cdot 0-10 \cdot 7$ \\
\hline Blue-veined cheese & $11 / 112$ & $9 \cdot 8$ & $5 / 85$ & $5 \cdot 9$ & 1.9 & $0 \cdot 5-7 \cdot 2$ & $0 / 19$ & $0 \cdot 0$ & $0 / 12$ & $0 \cdot 0$ & $*$ & \\
\hline Fetta & $16 / 112$ & $14 \cdot 3$ & $7 / 85$ & $8 \cdot 2$ & 1.9 & $0 \cdot 6-5 \cdot 7$ & $3 / 19$ & $15 \cdot 8$ & $2 / 12$ & $16 \cdot 7$ & $0.8 \dagger$ & $0 \cdot 0-10 \cdot 7$ \\
\hline Mussels & $6 / 112$ & $5 \cdot 4$ & $4 / 85$ & $4 \cdot 7$ & $2 \cdot 2$ & $0 \cdot 5-10 \cdot 0$ & $1 / 19$ & $5 \cdot 3$ & $0 / 12$ & $0 \cdot 0$ & $*$ & \\
\hline
\end{tabular}

mOR, Matched odds ratio; CI, confidence interval.

* Unable to calculate as numerator or denominator $=0$ in matched analysis.

$\dagger$ Median unbiased estimates.

\section{DISCUSSION}

This first national case-control study of listeriosis in Australia provides evidence to support existing listeriosis prevention policies but also highlights the need for an increased focus on preventing listeriosis in non-English speaking people and their families and increased attention to safety of food service in hospitals.

The associations between perinatal infections and living in a household where a LOTE was spoken and the tendency to report lower rates of being warned about the risks of listeriosis in this group suggest that a focus should be placed on preventing illness in nonEnglish speaking pregnant mothers. Speaking a LOTE cannot, of itself, be a risk factor for listeriosis. It may be a surrogate for lack of information on how to prevent listeriosis infection or a cultural marker for the consumption of high-risk foods. The low number of controls reporting living in a household where a LOTE is spoken is probably due in part to bias introduced through lack of adherence to a systematic selection of controls leading to an artificially low rate in the controls. It is possible that clinics may have broken the protocol and preferentially approached potential controls with a good command of English leading to an overestimate of LOTE as a risk factor. Nevertheless, $68 \%$ of cases reported living in a household where a LOTE is spoken compared to only $21 \%$ of the community reporting speaking a LOTE in the 2006 Census which suggests a real association, perhaps through a surrogate pathway, between speaking a LOTE and listeriosis [7]. This supports the need for review of food safety warnings in languages other than English. The Food Standards Australia and New Zealand (FSANZ) website only provides a brochure on listeriosis and food in English [8]. Languages used in State and Territory brochures vary widely with some only including English while others provide up to 14 languages other than English. While the lower frequency of reporting prior Listeria prevention messages by LOTE cases compared to non-LOTE cases is not significant it is still a concerning finding and is consistent with lower availability of educational material in languages other than English.

The increased usage of gastric acid inhibitors in the month before illness in listeriosis cases compared to controls in our study is consistent with findings from other studies identifying acid suppression as a risk for bacterial enteric infection [9, 10]. While the association with gastric acid inhibitors may have been confounded by comorbid factors that were not appropriately controlled for in the matching process, at least one study found that current users, but not former users, of $\mathrm{H} 2$ antagonists were at increased risk for salmonellosis infection [9]. Additionally, antacid and cimetidine administration were associated with listeriosis infection in case-control studies that attempted to control for comorbid conditions [11]. Long-term $\mathrm{H} 2$ antagonist therapy has been associated with an increased risk of faecal carriage of L. monocytogenes and animal studies have confirmed that decreasing gastric acidity in rats increases the risk of L. monocytogenes infection $[12,13]$. 
Eighteen hospitalized patients with immunocompromising conditions consumed high-risk foods that Australian food safety agencies recommend should be avoided by persons at risk for listeriosis. Surveys of long-term care facilities in the USA have identified that high-risk foods are often served to residents aged $>65$ years [14]. In October 2007, a new national food safety standard was gazetted that requires businesses and institutions that provide food service to vulnerable persons, such as in hospitals and aged care institutions, to implement a documented and audited food safety programme by October 2008 [15].

It is very difficult to provide robust food safety information to immunocompromised people, as they are not a homogeneous group and clinicians and patients cannot easily predict risk of infection in individuals. Pregnancy is an ideal time to provide counselling on the risk of Listeria infection and this complements counselling on healthy eating in pregnancy in antenatal clinics and classes. One study conducted in Australia found that only 13\% of Englishspeaking pregnant women were able to identify all six high-risk foods in a survey and women from a nonEnglish speaking background were 12 times more likely to select 'don't know' when asked about a range of high-risk foods [16].

Apart from the associations found with camembert and chopped liver/liverwurst consumption this study did not identify any other particular food as a substantial contributor to listeriosis. Identifying high-risk foods in a case-control study that spans multiple years is more challenging than in a single outbreak incident as the rate of contamination of even high-risk foods may vary widely over time. Subtyping of the Listeria isolates with comparison to food isolates may increase the chance of identifying high-risk foods with subtype concordance and efforts to uniformly subtype isolates from each jurisdiction are in progress. However, in Australia subtyping for listeriosis is usually only performed when outbreaks are identified. In future studies consideration should be given to the use of casecase comparison assisted by routine subtyping of all isolates - as used in the study by Varma et al. [17]. In the USA, PulseNet provides a national system for the uniform subtyping, comparison and archiving of L. monocytogenes strains [18]. Such a system would assist the recognition and investigation of outbreaks and development of a standardized national database of clinical L. monocytogenes isolate subtypes in Australia should be a priority.
Our study may have had limited power to detect high-risk foods due to small numbers, particularly for perinatal cases, where we only recruited 19 cases and 12 controls.

The study conducted by Varma et al. [17] identified a significant association with melons consumed in a commercial establishment and hummus prepared in a commercial establishment. No link with acidsuppressing medication was identified. In this study an association with rockmelon or cantaloupe approached significance in the univariate analysis but not the multivariate analysis. Place of consumption was not collected for rockmelon, nor was hummus exposure.

There are many other limitations to this study. We had difficulty recruiting controls from busy clinics. Food recall over multiple weeks is difficult, and it is likely that this study examines usual food preferences rather than exact exposures. The use of proxies for deceased cases may have led to exposure misclassification.

Hospitals and aged care institutions should ensure that food safety programmes for food service to vulnerable persons comply with the new standard, particularly in regard to the exclusion of high-risk foods. Auditing of the programmes should pay special attention to exclusion of potentially hazardous foods where the facility may not have the capacity to identify, validate and monitor hazard control interventions for those foods. This study identified that listeriosis prevention messages need to be disseminated in multiple languages and primary-care practitioners should ensure that patients from households speaking a LOTE receive counselling on listeriosis prevention.

This study adds to the concern associated with acid suppression removing a barrier to bacterial infection. There may be a place for counselling of patients taking such medications or a warning on the product insert regarding the potential increased risk of bacterial enteric infection.

Listeriosis is a serious and preventable foodborne infection for which vulnerable populations and highrisk foods have been known for many decades. While surveillance can be further enhanced to develop food safety policy into the future, it is important that both the well established vulnerable populations and newly recognized LOTE groups are protected as soon as possible. The effectiveness of the implementation of the new food safety programmes for food service to vulnerable persons should be carefully evaluated to ensure optimal protection of this group. 


\section{ACKNOWLEDGEMENTS}

We thank Dot Little for data management and Katerina Lewandowski for data quality and analysis work, Joy Gregory for assistance with review of the methodology and in initiating and conducting the study, and the many interviewers, patients and carers who contributed to the study. This study was conducted under the OzFoodNet programme of work and was funded by the Australian Government Department of Health \& Ageing and NSW Health through the Hunter Medical Research Institute.

\section{DECLARATION OF INTEREST}

None.

\section{REFERENCES}

1. Farber JM, Peterkin PI. Listeria monocytogenes, a food borne pathogen [published erratum appears in Microbiological Reviews 1991; 55: 752]. Microbiological Reviews 1991; 55: 476-511.

2. Schlech WF. Foodborne listeriosis. Clinical Infectious Diseases 2000; 31: 770-775.

3. Anon. 2006 annual report: OzFoodNet Working Group. Monitoring the incidence and causes of diseases potentially transmitted by food in Australia: annual report of the OzfoodNet Network, 2006. Communicable Diseases Intelligence $2007 ; 31$ : 345-65.

4. FDA/Center for Food Safety and Applied Nutrition. Quantitative assessment of relative risk to public health from foodborne Listeria monocytogenes among selected categories of ready-to-eat foods, 2003.

5. Dalton CB, et al. Foodborne disease outbreaks in Australia, 1995 to 2000. Communicable Diseases Intelligence 2004 ; 28 : 211-224.

6. Mitchell DL. A case cluster of listeriosis in Tasmania. Communicable Diseases Intelligence 1991; 15: 427.

7. Australian Bureau of Statistics. 2006 Census of Population and Housing.
8. Food Standards Australia. Listeria and Food brochure (http://www.foodstandards.gov.au/_srcfiles/Listeria. pdf). Accessed 18 December 2009.

9. Neal RK, et al. Recent treatment with $\mathrm{H} 2$ antagonists and antibiotics and gastric surgery as risk factors for salmonella infection. British Medical Journal 1994; 308: 176.

10. Leonard J, Marshall JK, Moayyedi P. Systematic review of the risk of enteric infection in patients taking acid suppression. American Journal of Gastroenterology 2007; 102: 2047-2056.

11. Ho JL, et al. An outbreak of type $4 \mathrm{~b}$ Listeria monocytogenes infection involving patients from eight Boston hospitals. Archives of Internal Medicine 1986; 146: 520-524.

12. Cobb CA, et al. Increased prevalence of Listeria monocytogenes in the faeces of patients receiving long-term H2 antagonists. European Journal of Gastroenterology and Hepatology 1996; 8: 1071-1074.

13. Schlech WF, Chase DP, Badley A. A model of foodborne Listeria monocytogenes infection in the SpragueDawney rat using gastric inoculation: development and effect of gastric acidity on infective dose. International Journal of Food Microbiology 1993; 18: 15-24.

14. Nelson JM, et al. FoodNet Emerging Infections Program Working Group. FoodNet survey of food use and practices in long-term care facilities. Journal of Food Protection 2008; 71 : 365-372.

15. FSANZ Standard 3.3.1. Food safety programs for food service to vulnerable persons (http://www.foodstandards. gov.au/thecode/foodsafetystandardsaustraliaonly/ standard331foodsafet3808.cfm). Accessed 29 September 2008.

16. Torvaldsen $\mathbf{S}$, et al. Listeria awareness among new mothers in Western Australia. Australian \& New Zealand Journal of Public Health 1999; 23: 362-367.

17. Varma JK, et al. Listeria monocytogenes infection from foods prepared in a commercial establishment: a casecontrol study of potential sources of sporadic illness in the United States. Clinical Infectious Diseases 2007; 44: 521-528.

18. Swaminathan B, et al. PulseNet: the molecular subtyping network for foodborne bacterial disease surveillance-United States. Emerging Infectious Diseases $2001 ; 7: 382-389$. 
Appendix Table 1. Additional case-specific risk factors for non-perinatal and perinatal listeriosis, Australia, $2001-2004$

\begin{tabular}{|c|c|c|c|c|c|c|c|c|c|c|c|c|}
\hline \multirow[b]{3}{*}{ Risk factor } & \multicolumn{6}{|c|}{ Non-perinatal } & \multicolumn{6}{|c|}{ Perinatal } \\
\hline & \multicolumn{2}{|c|}{$\begin{array}{l}\text { Cases } \\
\text { exposed }\end{array}$} & \multicolumn{2}{|c|}{$\begin{array}{l}\text { Controls } \\
\text { exposed }\end{array}$} & \multirow[b]{2}{*}{$\mathrm{mOR}$} & \multirow[b]{2}{*}{$95 \% \mathrm{CI}$} & \multicolumn{2}{|c|}{$\begin{array}{l}\text { Cases } \\
\text { exposed }\end{array}$} & \multicolumn{2}{|c|}{$\begin{array}{l}\text { Controls } \\
\text { exposed }\end{array}$} & \multirow{2}{*}{$\begin{array}{l}\text { Exact } \\
(\mathrm{mOR})\end{array}$} & \multirow[b]{2}{*}{$95 \% \mathrm{CI}$} \\
\hline & $n$ & $\%$ & $n$ & $\%$ & & & $n$ & $\%$ & $n$ & $\%$ & & \\
\hline Gender - male & $61 / 117$ & $52 \cdot 1$ & $53 / 85$ & $62 \cdot 4$ & $0 \cdot 7$ & $0 \cdot 3-1 \cdot 9$ & $0 / 19$ & $0 \cdot 0$ & $0 / 12$ & $0 \cdot 0$ & $*$ & \\
\hline Age & & & & & $1 \cdot 1$ & $1 \cdot 0-1 \cdot 1$ & & & & & $1 \cdot 0$ & $0 \cdot 9-1 \cdot 2$ \\
\hline \multicolumn{13}{|l|}{ Rurality } \\
\hline Inner city urban & $26 / 117$ & $22 \cdot 2$ & $5 / 85$ & $5 \cdot 9$ & Ref. & & $3 / 19$ & $15 \cdot 8$ & $1 / 12$ & $8 \cdot 3$ & Ref. & \\
\hline Suburban & $73 / 117$ & $62 \cdot 4$ & $70 / 85$ & $82 \cdot 4$ & $0 \cdot 5$ & $0 \cdot 1-2 \cdot 3$ & $13 / 19$ & $68 \cdot 4$ & $9 / 12$ & $75 \cdot 0$ & $0 \cdot 5$ & $0 \cdot 0-39 \cdot 3$ \\
\hline Town & $11 / 117$ & $9 \cdot 4$ & $7 / 85$ & $8 \cdot 2$ & $1 \cdot 2$ & $0 \cdot 2-8 \cdot 8$ & $1 / 19$ & $5 \cdot 3$ & $2 / 12$ & $16 \cdot 7$ & $1 \cdot 0 \dagger$ & $0 \cdot 0-39 \cdot 0$ \\
\hline Rural or remote & $7 / 117$ & $6 \cdot 0$ & $3 / 85$ & $3 \cdot 5$ & $1 \cdot 6$ & $0 \cdot 2-13 \cdot 3$ & $2 / 19$ & $10 \cdot 5$ & $0 / 12$ & $0 \cdot 0$ & $1 \cdot 0$ & $0 \cdot 0$-undefined \\
\hline \multicolumn{13}{|l|}{ Education level } \\
\hline Primary school & $7 / 117$ & $6 \cdot 0$ & $9 / 85$ & $10 \cdot 6$ & Ref. & & $0 / 19$ & $0 \cdot 0$ & $0 / 12$ & $0 \cdot 0$ & Ref. & \\
\hline Secondary school & $32 / 117$ & $27 \cdot 4$ & $32 / 85$ & $37 \cdot 7$ & $1 \cdot 2$ & $0 \cdot 3-4 \cdot 6$ & $5 / 19$ & $26 \cdot 3$ & $6 / 12$ & $50 \cdot 0$ & $*$ & \\
\hline Apprenticeship & $3 / 117$ & $2 \cdot 6$ & $2 / 85$ & $2 \cdot 4$ & $2 \cdot 2$ & $0 \cdot 2-23 \cdot 2$ & $1 / 19$ & $5 \cdot 3$ & $0 / 12$ & $0 \cdot 0$ & $1 \cdot 0$ & $0 \cdot 0$-undefined \\
\hline Certificate or diploma & $14 / 117$ & $12 \cdot 0$ & $18 / 85$ & $21 \cdot 2$ & $1 \cdot 3$ & $0 \cdot 3-5 \cdot 7$ & $0 / 19$ & $0 \cdot 0$ & $3 / 12$ & $25 \cdot 0$ & $1 \cdot 0 \dagger$ & $0 \cdot 0-13 \cdot 0$ \\
\hline University degree & $18 / 117$ & $15 \cdot 4$ & $21 / 85$ & $24 \cdot 7$ & $1 \cdot 0$ & $0 \cdot 2-4 \cdot 1$ & $5 / 19$ & $26 \cdot 3$ & $3 / 12$ & $25 \cdot 0$ & $4 \cdot 4$ & $0 \cdot 3-236 \cdot 2$ \\
\hline $\begin{array}{l}\text { Other/missing/ } \\
\text { refused/don't know }\end{array}$ & $43 / 117$ & $36 \cdot 8$ & $3 / 85$ & $3 \cdot 5$ & $3 \cdot 9$ & $0 \cdot 5-27 \cdot 6$ & $8 / 19$ & $42 \cdot 1$ & $0 / 12$ & $0 \cdot 0$ & $1 \cdot 0$ & $0 \cdot 0$-undefined \\
\hline \multicolumn{13}{|l|}{ Income level (AUS\$) } \\
\hline$<25000$ & $40 / 117$ & $34 \cdot 2$ & $41 / 85$ & $48 \cdot 2$ & Ref. & & $3 / 19$ & $15 \cdot 8$ & $3 / 12$ & $25 \cdot 0$ & Ref. & \\
\hline $25000-50000$ & $12 / 117$ & $10 \cdot 3$ & $16 / 85$ & $18 \cdot 8$ & $0 \cdot 7$ & $0 \cdot 2-2 \cdot 4$ & $5 / 19$ & $26 \cdot 3$ & $4 / 12$ & $33 \cdot 3$ & $2 \cdot 0$ & $0 \cdot 0-195 \cdot 8$ \\
\hline$>50000-100000$ & $10 / 117$ & $8 \cdot 6$ & $9 / 85$ & $10 \cdot 6$ & $0 \cdot 8$ & $0 \cdot 2-3 \cdot 9$ & $1 / 19$ & $5 \cdot 3$ & $2 / 12$ & $16 \cdot 7$ & $1 \cdot 6$ & $0 \cdot 0-130 \cdot 8$ \\
\hline$>100000$ & $2 / 117$ & $1 \cdot 7$ & $0 / 85$ & $0 \cdot 0$ & $*$ & $*$ & $1 / 19$ & $5 \cdot 3$ & $1 / 12$ & $8 \cdot 3$ & $10 \cdot 0 \dagger$ & $0 \cdot 0-390 \cdot 0$ \\
\hline $\begin{array}{l}\text { Missing/refused/ } \\
\text { don't know }\end{array}$ & $53 / 117$ & $45 \cdot 3$ & $19 / 85$ & $22 \cdot 4$ & $0 \cdot 9$ & $0 \cdot 3-2 \cdot 6$ & $9 / 19$ & $47 \cdot 4$ & $2 / 12$ & $16 \cdot 7$ & $1 \cdot 4$ & $0 \cdot 01-195 \cdot 4$ \\
\hline \multicolumn{13}{|l|}{ Prior medications } \\
\hline Cyclosporine & $4 / 117$ & $3 \cdot 4$ & $4 / 85$ & $4 \cdot 7$ & $*$ & $*$ & $0 / 19$ & $0 \cdot 0$ & $0 / 12$ & $0 \cdot 0$ & $*$ & \\
\hline Chemotherapy & $30 / 117$ & $25 \cdot 6$ & $20 / 85$ & $23 \cdot 5$ & $1 \cdot 7$ & $0 \cdot 6-5 \cdot 0$ & $0 / 19$ & $0 \cdot 0$ & $0 / 12$ & $0 \cdot 0$ & $*$ & \\
\hline Radiation therapy & $9 / 117$ & $7 \cdot 7$ & $5 / 85$ & $5 \cdot 9$ & $0 \cdot 8$ & $0 \cdot 1-4 \cdot 4$ & $0 / 19$ & $0 \cdot 0$ & $0 / 12$ & $0 \cdot 0$ & $*$ & \\
\hline Antidiarrhoeal agent & $15 / 117$ & $12 \cdot 8$ & $7 / 85$ & $8 \cdot 2$ & $3 \cdot 4$ & $0 \cdot 8-14 \cdot 6$ & $0 / 19$ & $0 \cdot 0$ & $0 / 12$ & $0 \cdot 0$ & $*$ & \\
\hline Other medication & $62 / 117$ & $53 \cdot 0$ & $49 / 85$ & $57 \cdot 7$ & $1 \cdot 3$ & $0 \cdot 6-2 \cdot 8$ & $3 / 19$ & $15 \cdot 8$ & $0 / 12$ & $0 \cdot 0$ & $4 \cdot 8 \dagger$ & $0 \cdot 4$-undefined \\
\hline
\end{tabular}

mOR, Matched odds ratio; CI, confidence interval.

* Unable to calculate as numerator or denominator $=0$ in matched analysis.

$\uparrow$ Median unbiased estimates. 
Appendix Table 2. Additional food-specific risk factors for non-perinatal and perinatal listeriosis

\begin{tabular}{|c|c|c|c|c|c|c|c|c|c|c|c|c|}
\hline \multirow[b]{3}{*}{ Risk factor - foods } & \multicolumn{6}{|c|}{ Non-perinatal } & \multicolumn{6}{|c|}{ Perinatal } \\
\hline & \multicolumn{2}{|l|}{$\begin{array}{l}\text { Cases } \\
\text { exposed }\end{array}$} & \multicolumn{2}{|c|}{$\begin{array}{l}\text { Controls } \\
\text { exposed }\end{array}$} & \multirow[b]{2}{*}{$\mathrm{mOR}$} & \multirow[b]{2}{*}{$95 \% \mathrm{CI}$} & \multicolumn{2}{|c|}{$\begin{array}{l}\text { Cases } \\
\text { exposed }\end{array}$} & \multicolumn{2}{|c|}{$\begin{array}{l}\text { Controls } \\
\text { exposed }\end{array}$} & \multirow{2}{*}{$\begin{array}{l}\text { Exact } \\
(\mathrm{mOR})\end{array}$} & \multirow[b]{2}{*}{$95 \% \mathrm{CI}$} \\
\hline & $n$ & $\%$ & $n$ & $\%$ & & & $n$ & $\%$ & $n$ & $\%$ & & \\
\hline Self-serve salad bar & $7 / 112$ & $6 \cdot 3$ & $13 / 85$ & $15 \cdot 3$ & $0 \cdot 7$ & $0 \cdot 2-2 \cdot 0$ & $2 / 19$ & $10 \cdot 5$ & $3 / 12$ & $25 \cdot 0$ & $1 \cdot 4$ & $0 \cdot 1-21 \cdot 7$ \\
\hline Lettuce & $70 / 112$ & $62 \cdot 5$ & $62 / 85$ & $72 \cdot 9$ & $1 \cdot 1$ & $0 \cdot 5-2 \cdot 7$ & $12 / 19$ & $63 \cdot 2$ & $8 / 12$ & $66 \cdot 7$ & $1 \cdot 0$ & $0 \cdot 1-59 \cdot 0$ \\
\hline $\begin{array}{l}\text { Prepacked bagged } \\
\text { coleslaw }\end{array}$ & $7 / 112$ & $6 \cdot 3$ & $10 / 85$ & $11 \cdot 8$ & $0 \cdot 8$ & $0 \cdot 2-2 \cdot 7$ & $2 / 19$ & $10 \cdot 5$ & $0 / 12$ & $0 \cdot 0$ & $*$ & \\
\hline Strawberries & $42 / 112$ & $37 \cdot 5$ & $35 / 85$ & $41 \cdot 2$ & 0.9 & $0 \cdot 4-2 \cdot 0$ & $9 / 19$ & $47 \cdot 4$ & $4 / 12$ & $33 \cdot 3$ & $1 \cdot 6$ & $0 \cdot 2-12 \cdot 7$ \\
\hline Alfalfa/pea sprouts & $10 / 112$ & $8 \cdot 9$ & $15 / 85$ & $17 \cdot 7$ & $0 \cdot 4$ & $0 \cdot 1-1 \cdot 5$ & $2 / 19$ & $10 \cdot 5$ & $2 / 12$ & $16 \cdot 7$ & $0 \cdot 8 \dagger$ & $0-10 \cdot 7$ \\
\hline Any fresh juice & $11 / 112$ & $9 \cdot 8$ & $19 / 85$ & $22 \cdot 4$ & $0 \cdot 3$ & $0 \cdot 1-1 \cdot 0$ & $4 / 19$ & $21 \cdot 1$ & $0 / 12$ & $0 \cdot 0$ & $2 \cdot 0 \dagger$ & $0 \cdot 1$-undefined \\
\hline $\begin{array}{l}\text { Any fresh } \\
\text { juice - high risk }\end{array}$ & $7 / 112$ & $6 \cdot 3$ & $11 / 85$ & $12 \cdot 9$ & $0 \cdot 5$ & $0 \cdot 1-2 \cdot 6$ & $3 / 19$ & $15 \cdot 8$ & $0 / 12$ & $0 \cdot 0$ & $2 \cdot 0 \dagger$ & $0 \cdot 1$-undefined \\
\hline Organic produce & $11 / 112$ & $9 \cdot 8$ & $11 / 85$ & $12 \cdot 9$ & 0.6 & $0 \cdot 2-2 \cdot 0$ & $3 / 19$ & $15 \cdot 8$ & $1 / 12$ & $8 \cdot 3$ & $2 \cdot 0$ & $0 \cdot 0-157 \cdot 0$ \\
\hline Ready to eat coleslaw & $12 / 112$ & $10 \cdot 7$ & $27 / 85$ & $31 \cdot 8$ & $0 \cdot 3$ & $0 \cdot 1-0 \cdot 9$ & $3 / 19$ & $15 \cdot 8$ & $2 / 12$ & $16 \cdot 7$ & $1 \cdot 0$ & $0 \cdot 0-98 \cdot 0$ \\
\hline $\begin{array}{l}\text { Deli meat or cold } \\
\text { cuts of meat }\end{array}$ & $84 / 112$ & $75 \cdot 0$ & $73 / 85$ & $85 \cdot 9$ & $0 \cdot 6$ & $0 \cdot 2-1 \cdot 6$ & $16 / 19$ & $84 \cdot 2$ & $12 / 12$ & $100 \cdot 0$ & $0 \cdot 5 \dagger$ & $0 \cdot 0-19 \cdot 5$ \\
\hline $\begin{array}{l}\text { Deli meat/cold } \\
\text { cuts - high risk }\end{array}$ & $83 / 112$ & $74 \cdot 1$ & $71 / 85$ & $83 \cdot 5$ & $0 \cdot 6$ & $0 \cdot 3-1 \cdot 6$ & $15 / 19$ & $79 \cdot 0$ & $12 / 12$ & $100 \cdot 0$ & $0.5 \dagger$ & $0 \cdot 0-19 \cdot 5$ \\
\hline Barbequed chicken & $33 / 112$ & $29 \cdot 5$ & $35 / 85$ & $41 \cdot 2$ & $0 \cdot 6$ & $0 \cdot 3-1 \cdot 4$ & $11 / 19$ & $57 \cdot 9$ & $8 / 12$ & $66 \cdot 7$ & $1 \cdot 0$ & $0 \cdot 1-16 \cdot 0$ \\
\hline $\begin{array}{l}\text { Devon/luncheon meat/ } \\
\text { luncheon loaf }\end{array}$ & $8 / 112$ & $7 \cdot 1$ & $5 / 85$ & $5 \cdot 9$ & $0 \cdot 6$ & $0 \cdot 1-3 \cdot 4$ & $1 / 19$ & $5 \cdot 3$ & $2 / 12$ & $16 \cdot 7$ & $0 \cdot 8 \dagger$ & $0 \cdot 0-10 \cdot 7$ \\
\hline Ham & $63 / 112$ & $56 \cdot 3$ & $55 / 85$ & $64 \cdot 7$ & $0 \cdot 6$ & $0 \cdot 3-1 \cdot 3$ & $8 / 19$ & $42 \cdot 1$ & $11 / 12$ & $91 \cdot 7$ & $0 \cdot 1 \dagger$ & $0 \cdot 0$ \\
\hline Pepperoni & $15 / 112$ & $13 \cdot 4$ & $12 / 85$ & $14 \cdot 1$ & 0.9 & $0 \cdot 3-2 \cdot 5$ & $3 / 19$ & $15 \cdot 8$ & $3 / 12$ & $25 \cdot 0$ & $1 \cdot 4$ & $0 \cdot 1-21 \cdot 7$ \\
\hline Pate & $4 / 112$ & $3 \cdot 6$ & $3 / 85$ & $3 \cdot 5$ & $0 \cdot 6$ & $0 \cdot 1-5 \cdot 4$ & $1 / 19$ & $5 \cdot 3$ & $0 / 12$ & $0 \cdot 0$ & $*$ & \\
\hline Other meat & $29 / 112$ & $25 \cdot 9$ & $21 / 85$ & $24 \cdot 7$ & $1 \cdot 4$ & $0 \cdot 7-3 \cdot 2$ & $4 / 19$ & $21 \cdot 1$ & $2 / 12$ & $16 \cdot 7$ & $1 \cdot 0$ & $0 \cdot 0-19 \cdot 2$ \\
\hline Other meat - high risk & $20 / 112$ & $17 \cdot 9$ & $13 / 85$ & $15 \cdot 3$ & $2 \cdot 2$ & $0 \cdot 8-5 \cdot 6$ & $3 / 19$ & $15 \cdot 8$ & $0 / 12$ & $0 \cdot 0$ & $2 \cdot 0 \dagger$ & $0 \cdot 1$-undefined \\
\hline Frankfurter/hot dog & $14 / 112$ & $12 \cdot 5$ & $15 / 85$ & $17 \cdot 7$ & $0 \cdot 9$ & $0 \cdot 3-2 \cdot 3$ & $3 / 19$ & $15 \cdot 8$ & $2 / 12$ & $16 \cdot 7$ & $0 \cdot 8 \dagger$ & $0 \cdot 0-10 \cdot 7$ \\
\hline Any cheese & $67 / 112$ & $59 \cdot 8$ & $38 / 85$ & $44 \cdot 7$ & $1 \cdot 8$ & $0 \cdot 9-3 \cdot 6$ & $10 / 19$ & $52 \cdot 6$ & $5 / 12$ & $41 \cdot 7$ & $0 \cdot 6$ & $0 \cdot 0-13 \cdot 4$ \\
\hline Brie & $11 / 112$ & $9 \cdot 8$ & $11 / 85$ & $12 \cdot 9$ & 0.9 & $0 \cdot 3-2 \cdot 6$ & $0 / 19$ & $0 \cdot 0$ & $0 / 12$ & $0 \cdot 0$ & $*$ & \\
\hline Cream cheese & $13 / 112$ & $11 \cdot 6$ & $8 / 85$ & $9 \cdot 4$ & $1 \cdot 4$ & $0 \cdot 5-4 \cdot 2$ & $1 / 19$ & $5 \cdot 3$ & $0 / 12$ & $0 \cdot 0$ & $2 \cdot 0 \dagger$ & $0 \cdot 1$-undefined \\
\hline Ricotta & $12 / 112$ & $10 \cdot 7$ & $4 / 85$ & $4 \cdot 7$ & $1 \cdot 3$ & $0 \cdot 3-6 \cdot 1$ & $0 / 19$ & $0 \cdot 0$ & $0 / 12$ & $0 \cdot 0$ & $*$ & \\
\hline Mozarella & $12 / 112$ & $10 \cdot 7$ & $5 / 85$ & $5 \cdot 9$ & $1 \cdot 6$ & $0 \cdot 2-10 \cdot 1$ & $3 / 19$ & $15 \cdot 8$ & $0 / 12$ & $0 \cdot 0$ & $*$ & \\
\hline Other soft cheese & $10 / 112$ & $8 \cdot 9$ & $9 / 85$ & $10 \cdot 6$ & $0 \cdot 4$ & $0 \cdot 1-2 \cdot 0$ & $2 / 19$ & $10 \cdot 5$ & $0 / 12$ & $0 \cdot 0$ & $*$ & \\
\hline $\begin{array}{l}\text { Raw or unpasteurized } \\
\text { milk }\end{array}$ & $1 / 112$ & $0 \cdot 9$ & $0 / 85$ & $0 \cdot 0$ & $*$ & $*$ & $1 / 19$ & $5 \cdot 3$ & $0 / 12$ & $0 \cdot 0$ & $*$ & \\
\hline Prawns & $24 / 112$ & $21 \cdot 4$ & $28 / 85$ & $32 \cdot 9$ & $0 \cdot 8$ & $0 \cdot 4-1 \cdot 8$ & $3 / 19$ & $15 \cdot 8$ & $2 / 12$ & $16 \cdot 7$ & $0 \cdot 8 \dagger$ & $0-10 \cdot 7$ \\
\hline Oysters & $8 / 112$ & $7 \cdot 1$ & $8 / 85$ & $9 \cdot 4$ & $0 \cdot 7$ & $0 \cdot 2-2 \cdot 7$ & $1 / 19$ & $5 \cdot 3$ & $2 / 12$ & $16 \cdot 7$ & $0 \cdot 8 \dagger$ & $0-10 \cdot 7$ \\
\hline Smoked salmon/lox & $12 / 112$ & $10 \cdot 7$ & $11 / 85$ & $12 \cdot 9$ & $1 \cdot 3$ & $0 \cdot 4-4 \cdot 4$ & $0 / 19$ & $0 \cdot 0$ & $0 / 12$ & $0 \cdot 0$ & $*$ & \\
\hline Other smoked fish & $8 / 112$ & $7 \cdot 1$ & $11 / 85$ & $12 \cdot 9$ & $0 \cdot 5$ & $0 \cdot 1-1 \cdot 8$ & $0 / 19$ & $0 \cdot 0$ & $0 / 12$ & $0 \cdot 0$ & $*$ & \\
\hline
\end{tabular}

mOR, Matched odds ratio; CI, confidence interval.

* Unable to calculate as numerator or denominator $=0$ in matched analysis.

$\dagger$ Median unbiased estimates. 